\title{
Preparation and photoluminescence study of Alumin o-boro silicate YAG fluorescent glass for White LED
}

\author{
Chao Yang ( $\sim 1245935574 @ q q . c o m)$ \\ Nantong University \\ Guohua Song \\ Nantong University \\ Jianwen Miao \\ Nantong University \\ Tingting Fan \\ Nantong University
}

\section{Research Article}

Keywords: white LED, YAG: Eu3+, fluorescent glass

Posted Date: March 30th, 2021

DOI: https://doi.org/10.21203/rs.3.rs-349946/v1

License: (c) (i) This work is licensed under a Creative Commons Attribution 4.0 International License. Read Full License 


\section{Abstract}

The YAG: Eu 3+ fluorescent glass for NUV(near ultraviolet) white LEDs was obtained firstly by synthesizing Y 3 Al 5012 (YAG): Eu 3+ precursors through a simple co-precipitation method, and then mixing precursor with B 203 -Al 203 -SiO 2 -Na 2 O-BaO glass powder calcined at $1400^{\circ} \mathrm{C}$ for 2.5 hours. The as-prepared YAG glass-ceramic phosphor was investigated by DTA, XRD, SEM, and photoluminescence (PL). Influence of YAG: Eu 3+ precursor and Eu 3+ doping on excitation and emission spectra also have been studied. The results show that: the phosphor's emission peak located at $393 \mathrm{~nm}$ is correspond to the 7 F 0 - 5 L 6 transition of Eu 3+ ions, which matches good with UV LED chips; the phosphor gives intense emission at 593nm originating from the $5 \mathrm{D} 0-7 \mathrm{~F} 1$ transition of Eu 3+ ions. When the YAG precursor is $0.9 \mathrm{~g}$ and amount of Eu $3+$ doped is 0.08 , the fluorescence excitation spectra of glass and emission spectra of the peak intensity reach its maximum value. The YAG: Eu 3+ fluorescence glass could be a promising material for the production of near ultraviolet chip white lightemitting diode.

\section{Introduction}

White light emitting diode light source with a low driving voltage, applicability, high stability, short response time, mercury and lead pollution, monochromatic light etc., will be the most promising lightning source, which will replace the incandescent, fluorescent, high intensity gas discharge lamp in the 21 century $[1,2]$. Currently people use blue LED chip coated with yellowish phosphor of YAG to achieve white LED, its color temperature is usually higher than $5000 \mathrm{~K}$, the general color rendering index also is less than 80. Optical parameter of white LEDs will change after a period time of using as the light-emitting chip and phosphors have different life span; additionally, when the phosphor is heated by LED chips, it will accelerate phosphor deterioration, luminousness of organic encapsulating material also will decline, making the life span of white LED decrease $[3,4,5]$. Although RGB LED chips of white LED have relatively wide and low color temperature range, it can easily achieve high color rendering index, but the RGB chips have different light attenuation coefficient, it needs to add appropriate control circuit $[1,6,7]$.

Using near-UV chips as excitation source to excite tribasic fluorescent powder has become a $\mathrm{n}$ international hot spot recently $[8,9,10]$. As the visual sensitivity of the near-UV is not obvious to human, we can achieve high color rendering index in a large range of color temperature. Near-UV excitation white LED is considered to lead new generation of white LED lighting direction [11,12]. YAG is widely used as laser and light-emitting substrate material for its excellent physical and chemical properties[13]; YAG phosphors doped with $\mathrm{Eu}^{3+}$ ions have a strong excitation peak in $395 \mathrm{~nm}$, which matches good with exciting wave band of near-UV LED chips and emit bright orange-red shade. The phosphor fluorescent glass makes excellent heat distribution in the glass material, which approximately equal to phosphor remote technology. Fluorescent glass has following advantages: simple production process, high light efficiency, low luminescence decay $[14,15,16,17]$. In this work we have prepared YAG: $\mathrm{Eu}^{3+}$ fluorescence glass in $\mathrm{B}_{2} \mathrm{O}_{3}-\mathrm{Al}_{2} \mathrm{O}_{3}-\mathrm{SiO}_{2}-\mathrm{Na}_{2} \mathrm{O}-\mathrm{BaO}$ system, its spectral properties, light-emitting properties also have been studied. 


\section{Materials And Methods}

\section{1 materials}

$\mathrm{Eu}_{2} \mathrm{O}_{3}(99.99 \%), \mathrm{Y}_{2} \mathrm{O}_{3}(99.99 \%), \mathrm{NH}_{3} \cdot \mathrm{H}_{2} \mathrm{O}(25-28 \%), \mathrm{HNO}_{3}(65-68 \%), \mathrm{CH}_{3} \mathrm{CH}_{2} \mathrm{OH}(99.7 \%), \mathrm{A} 1\left(\mathrm{NO}_{3}\right)_{3} \cdot 9 \mathrm{H}_{2} \mathrm{O}(\mathrm{AR})$, $\mathrm{NH}_{4} \mathrm{HCO}_{3}(\mathrm{AR}), \mathrm{Al}_{2} \mathrm{O}_{3}(\mathrm{AR}), \mathrm{Na}_{2} \mathrm{CO}_{3}(\mathrm{AR}), \mathrm{SiO}_{2}(\mathrm{AR}), \mathrm{H}_{3} \mathrm{BO}_{3}(\mathrm{AR}), \mathrm{BaCO}_{3}(\mathrm{AR})$ were used as starting materials.

First yttrium oxide and europium oxide were dissolved in dilute nitric acid respectively to obtain yttrium nitrate, europium nitrate and aluminum nitrate with concentration of $1 \mathrm{~mol} / \mathrm{L}$ metal ions solution. Then mix the above three kinds of solutions according to yttrium aluminum garnet $\mathrm{Y}_{3-\mathrm{x}} \mathrm{Eu}_{\mathrm{x}} \mathrm{Al}_{5} \mathrm{O}_{12}(\mathrm{x}=0,0.02$, $0.04,0.06,0.08,0.1)$ stoichiometric. Prepare $100 \mathrm{~mL}$ mixed precipitant with the composition of $\mathrm{NH}_{3} \cdot \mathrm{H}_{2} \mathrm{O}$ $2 \mathrm{~mol} / \mathrm{L}$ and $\mathrm{NH}_{4} \mathrm{HCO}_{3} 2 \mathrm{~mol} / \mathrm{L}$, then mix the three metal ion source by fap funnel with $3 \mathrm{~mL} / \mathrm{min}$ into mixed precipitator with constant temperature at $30^{\circ} \mathrm{C}$. Adjust mixture $\mathrm{pH}$ to 6.5 with ammonia swap around, then continue stirring $2 \mathrm{~h}$, aging for $12 \mathrm{~h}$; Discard the supernatant after centrifugation, wash precipitate precursor with deionized water four times, with ethanol three times, then put precipitate precursor into constant temperature oven with $120^{\circ} \mathrm{C}$ for $12 \mathrm{~h}$, obtain YAG: Eu ${ }^{3+}$ precursors by grinding at last[16].

The initial composition of the glass materials are $\mathrm{BaCO}_{3} 0.54 \mathrm{~g}, \mathrm{Na}_{2} \mathrm{CO}_{3} 0.217 \mathrm{~g}, \mathrm{H}_{3} \mathrm{BO}_{3} 0.478 \mathrm{~g}, \mathrm{SiO}_{2}$ $0.164 \mathrm{~g}, \mathrm{Al}_{2} \mathrm{O}_{3} 0.3 \mathrm{~g}$, add $\mathrm{YAG}$ precursor $(0.7 \mathrm{~g}, 0.8 \mathrm{~g}, 0.9 \mathrm{~g}, 1.0 \mathrm{~g}, 1.1 \mathrm{~g})$, and anhydrous ethanol. Grind these raw materials together for a long time, put the material into corundum crucible after drying, then put corundum crucible into atmosphere resistance furnace for $7 \mathrm{~h}$, insulate $2.5 \mathrm{~h}$ when the temperature reached $1400^{\circ} \mathrm{C}$, casting forming the sample in a muffle furnace after $550^{\circ} \mathrm{C}$ annealing $3 \mathrm{~h}$. Polish sample to form $1 \mathrm{~cm} \star 1 \mathrm{~cm}$ thin transparent fluorescent glass $[16,17]$.

\subsection{Characterization of YAG: $\mathrm{Eu}^{3+}$ Glass-ceramic}

Sample's crystal structure was scanned by ARL TRA X-ray diffraction (XRD). YAG precursor, the glass base and their mixture were analyzed with differential thermal analysis (DTA) by Netzsch STA-449F3 thermal analyzer. Sample morphology was scanned with Hitachi S3400 scanning electron microscope (SEM). Sample's excitation and emission spectra were measured by RF-5301PC fluorescence spectrophotometer.

\section{Results And Discussion}

\subsection{DTA-TGA analyze of YAG: $\mathrm{Eu}^{3+}$ fluorescent glass}

Fig. 1 shows the DTA-TGA curves of precursor during the calcination process. The precursor sample was synthesized by $1.74 \mathrm{~g} \mathrm{H}_{3} \mathrm{BO}_{3}-\mathrm{SiO}_{2}-\mathrm{Al}_{2} \mathrm{O}_{3}-\mathrm{Na}_{2} \mathrm{CO}_{3}-\mathrm{BaCO}_{3}$ adding $0.9 \mathrm{~g} \mathrm{Y}_{2.94} \mathrm{Eu}_{0.06} \mathrm{Al}_{5} \mathrm{O}_{12}$ by co-precipitation method. We can see that YAG precursor materials and glass initial homogeneous mixture loss $38 \%$ weight from room temperature to $300^{\circ} \mathrm{C}$, there is an endothermic peak at $68.4^{\circ} \mathrm{C}$ corresponding to the initial precursor materials and glass adsorption water loss; and there is a sharp endothermic peak at 
$203.8^{\circ} \mathrm{C}$, corresponding to the apparent weight loss TGA curve, which is the initial glass material loss of the crystal water. From $300^{\circ} \mathrm{C}$ to $1400^{\circ} \mathrm{C}$, there are about $40 \%$ weight loss and endothermic peak appeared separately at $662.7^{\circ} \mathrm{C}, 818.2^{\circ} \mathrm{C}$ and $938.7^{\circ} \mathrm{C}$, etc. There is more than one endothermic peak, which ascribe to the decomposition of boric acid and carbonate compounds, subsequent exothermic peak and formation of YAG crystal phase.

\subsection{XRD analyze of YAG: $\mathrm{Eu}^{3+}$ fluorescent glass}

The $\mathrm{Y}_{2.94} \mathrm{Eu}_{0.06} \mathrm{Al}_{5} \mathrm{O}_{12}$ fluorescent glass was synthesized by $1.74 \mathrm{~g}$ glass material and $0.9 \mathrm{~g}$ precursor, its XRD patterns was correspond with $\mathrm{Y}_{3} \mathrm{Al}_{5} \mathrm{O}_{12}$ standard map (PDF:79-1892). We can certificate that the crystal in glass-ceramic was YAG, which belong to body-centered cubic crystal system. The diffraction have relatively sharp peaks, which indicate that a small amount of rare earth ions $\mathrm{Eu}^{3+}$ replaces $\mathrm{Y}$ of the crystal lattice and crystallization of YAG phase was well mixed, and it does not affect the formation of YAG phase $[15,16,18]$; Fig. 2 shows the XRD patterns of glass material without YAG: $\mathrm{Eu}^{3+}$ glass precursor. There are not obvious diffraction peaks in the photo, which certificated that products have amorphous form.

\subsection{Excitation and emission spectra of YAG fluorescent glass}

\subsubsection{Influence of YAG fluorescent glass spectral characteristics under different content of YAG precursor}

Fig. 3 and Fig. 4 show the excitation and emission spectra of fluorescent glass with different quality $(0.7 \mathrm{~g}$, $0.8 \mathrm{~g}, 0.9 \mathrm{~g}, 1.0 \mathrm{~g}$ and $1.1 \mathrm{~g}$ ) of $\mathrm{Y}_{2.94} \mathrm{Eu}_{0.06} \mathrm{Al}_{5} \mathrm{O}_{12}$ precursor. The excitation spectra of YAG: $\mathrm{Eu}^{3+}$ fluorescence glass was detected at wavelength of $593 \mathrm{~nm}$, test range was $350 \sim 420 \mathrm{~nm}$. The strongest excitation peak was at $393 \mathrm{~nm}$, correspond to ${ }^{7} \mathrm{~F}_{0}{ }^{-5} \mathrm{~L}_{6}$ transition of $\mathrm{Eu}^{3+}$ ions, which belong to $\mathrm{Eu}^{3+}$ Characteristic absorption lines. The excitation spectra matches good with exciting wave band of near-UV LED chips, the other weak excitation peaks were ${ }^{7} \mathrm{D}_{0}-{ }^{-5} \mathrm{G}_{2}$ transition (peak at $381 \mathrm{~nm}$ ) and ${ }^{7} \mathrm{~F}_{0}-{ }^{-5} \mathrm{D}_{3}$ transition (peak at $416 \mathrm{~nm}$ ), etc. [17].

Fig.3 Excitation spectra of fluorescent glass with different content of precursor

Emission spectra was detected at wavelength of $393 \mathrm{~nm}$, test the range was $575 \sim 635 \mathrm{~nm}$. The strongest peak appears at $593 \mathrm{~nm}\left({ }^{5} \mathrm{D}_{0}{ }^{-7} \mathrm{~F}_{1}\right)$, which belong to the same transition with ${ }^{5} \mathrm{D}_{0}{ }^{-7} \mathrm{~F}_{1}$ transition at $598 \mathrm{~nm}$, emission spectra was orange. There are also two weak emission peak at $611 \mathrm{~nm}$ and $631 \mathrm{~nm}$, correspond to the ${ }^{5} D_{0}{ }^{7} F_{2}$ transition and the ${ }^{5} D_{0}{ }^{7} F_{4}$ transition. Symmetrical $Y^{3+}$ ions were replaced by $\mathrm{Eu}^{3+}$ ions In YAG crystal, so the emission peak is based on the magnetic dipole ${ }^{5} D_{0}{ }^{7} F_{1}$ transition (at $593 \mathrm{~nm}$ ) [17].

The peak wavelength of excitation and emission spectra of YAG fluorescent glass with different content of YAG precursor almost not change, but the spectra intensity have changed. 
When the content of YAG precursor is between $0.7 \sim 0.9 \mathrm{~g}$, the intensity of excitation and emission peaks increased; while the content of YAG precursor is between $0.9 \sim 1.1 \mathrm{~g}$, the intensity of excitation and emission peaks decreased. When the content of YAG precursor is $0.9 \mathrm{~g}$, the intensity of excitation and emission peaks reaches their maxium value. The change of precursor content lead to the excitation and emission peaks rise and fall as the initial mixture of materials and YAG glass precursor composition contains $\mathrm{Al}_{2} \mathrm{O}_{3}$. When the YAG precursor content decreased, during the high-temperature calcination process, $\mathrm{Al}_{2} \mathrm{O}_{3}$ in precursor will partly enter the glass base and become glass components, resulting in YAG crystal phase formation reducing. When the content of YAG: $\mathrm{Ce}^{3+}$ precursor is more than $0.9 \mathrm{~g}$, it led glass formation process decline. When the content of YAG: $\mathrm{Ce}^{3+}$ precursor is 1.0 and $1.1 \mathrm{~g}$, the vitreous loss through impact excitation and emission light reaches phosphor escape fluorescent glass surface, resulting in excitation and emission spectra intensity decreased [16].

\subsection{2 $\mathrm{Eu}^{3+}$ doped YAG fluorescence of the spectral characteristics of glass}

While keeping the calcination temperature at $1400^{\circ} \mathrm{C}$ for $2.5 \mathrm{~h}$ and other experimental conditions unchanged, we changed the $x$ value of the $\mathrm{Y}_{3-\mathrm{x}} \mathrm{Eu}_{-\mathrm{x}} \mathrm{Al}_{5} \mathrm{O}_{12}(\mathrm{x}=0.00 \sim 0.1)$ fluorescent glass, then test the excitation and emission spectral of fluorescent glass. Fig. 5 and Fig. 6 show the excitation and emission spectra of YAG fluorescent glass with the $x$ value under $0.00,0.02,0.04,0.06,0.08,0.1$.

It can be seen from the Fig. 5 and Fig. 6 that the excitation and emission spectra of the sample is composed by a set of spikes. As the $x$ value increases, the diffraction peaks corresponding to the wavelength unchanged, only the diffraction peak intensity increased, and no new diffraction peaks appears follow the sharp peak. When the $x$ value is less than 0.08 , the sample excitation and emission intensity will increase as $x$ increases; when $x$ is greater than 0.08 , the sample excitation and emission intensity will decrease as the $x$ value increases; when the amount of the $x$ value is equal to $0.08 \mathrm{Eu}^{3+}$, the excitation and emission spectra of the YAG: $\mathrm{Eu}^{3+}$ glass reach the maximum value, the peak value correspond to the ${ }^{7} \mathrm{~F}_{0}{ }^{-5} \mathrm{~L}_{6}$ and the ${ }^{5} \mathrm{D}_{0}{ }^{-7} \mathrm{~F}_{1}$ transition.

When the $\mathrm{x}$ value is less than $0.08, \mathrm{Eu}^{3+}$ ions will enter into the stroma and replace $\mathrm{Y}^{3+}$ ions as electron traps. The number of luminescent centers will increase with the $\mathrm{Eu}^{3+}$ ions concentration increases, it will make the electron trap in electron impact ionization of luminescence centers and luminescence centers with radiation or recombination probability of luminescence centers increase. When the $x$ value is greater than 0.08 , the excitation energy will deliver to the $\mathrm{Eu}^{3+}$ ions. The high energy will not stop in a step and energy transfer will proceed continuously due to the energy transfer between $\mathrm{Eu}^{3+}$ ions is very big. This will take excitation energy far away from the absorption site, energy migration appears. When the excitation energy reach the non-radiative energy (extinction or quenching site), the system luminous efficiency will decline due to the concentration quenching [19, 20, 21].

\section{Conclusion}


The YAG: $\mathrm{Eu}^{3+}$ fluorescent glass was obtained firstly by synthesizing $\mathrm{Y}_{3} \mathrm{Al}_{5} \mathrm{O}_{12}(\mathrm{YAG})$ : $\mathrm{Eu}^{3+}$ precursors through a simple co-precipitation method, and then mixing YAG: $\mathrm{Eu}^{3+}$ precursor with $\mathrm{B}_{2} \mathrm{O}_{3}-\mathrm{Al}_{2} \mathrm{O}_{3}-\mathrm{SiO}_{2}-$ $\mathrm{Na}_{2} \mathrm{O}-\mathrm{BaO}$ glass powder calcined at $1400^{\circ} \mathrm{C}$. The content of $\mathrm{YAG}$ precursor and $\mathrm{Eu}^{3+}$ ions doped in initial materials do not affect the fluorescence excitation and emission spectra of peak wavelength, but the value of the peak wavelength; when the YAG precursor is $0.9 \mathrm{~g}$ and amount of $\mathrm{Eu}^{3+}$ doped is 0.08 , the fluorescence excitation spectra of glass and emission spectra of the peak intensity reach its maximum value. The fluorescence excitation peak of the YAG: $\mathrm{Eu}^{3+}$ fluorescence glass is at $593 \mathrm{~nm}$, the emission peak is located at $393 \mathrm{~nm}$, and they basically have the same spectral characteristics with YAG: $\mathrm{Eu}^{3+}$ phosphors. The YAG: $\mathrm{Eu}^{3+}$ fluorescence glass could be a promising material for the production of near ultraviolet chip white light-emitting diode.

\section{References}

1. Ye, F. Xiao, Y.X. Pan, Y.Y. Ma, Q.Y. Zhang, Phosphors in phosphor-converted white light-emitting diodes: recent advances in materials, techniques and properties. Mater. Sci. Eng. R. 71, 1-34 (2011) https://doi.org/10.1016/j.mser.2010.07.001

2. W. Qiao, Z.C. Zhang, Z.G. Xia, Tuning of the compositions and multiple activator sites toward singlephased white emission in $\left(\mathrm{Ca}_{9-\mathrm{x}} \mathrm{Sr}_{\mathbf{x}}\right) \mathrm{MgK}\left(\mathrm{PO}_{4}\right)_{7}: \mathrm{Eu}^{2+}$ ohosphors for solid-state lighting. Inorg. Chem. 58, 5006-5012 (2019) https://doi.org/10.1021/acs.inorgchem.9b00028

3. S. Yoo, W.B. Lm, J.H. Kang, D.Y. Jeon, Preparation and photoluminescence properties of $\mathrm{YAl}_{3}\left(\mathrm{BO}_{3}\right)_{4}$ : $\mathrm{Tb}^{3+}, \mathrm{Bi}^{3+}$ phosphor under VUV/UV excitation. Opt. Mater. 31, 131-135 (2008) https://doi.org/10.1016/j.optmat.2008.02.005

4. S. Huang, A.J. Tang, C. Yang, H.F. Jin, Preparation, characterization and luminescence properties of a new hydrous red phosphor $\mathrm{CaB}_{3} \mathrm{O}_{5}(\mathrm{OH})$ : $\mathrm{Eu}^{3+}$ with different morphologies. Luminescence. 32, 217222 (2016) https://doi.org/10.1002/bio.3171

5. X. Wang, H.Q. Zhao, D.F. Sun, Luminescent properties of CaWO4: $\mathrm{Eu}^{3+}$ phosphors doped with $\mathrm{Mg}^{2+}$ or $\mathrm{Zn}^{2+}$. Chinese J. Lumin. 41, 23-30 (2020) https://doi.org/10.3788/fgxb20204101.0023

6. T. Chen, S.C. Tan, S.Y. Hui, Nonlinear dimming and correlated color temperture control of bicolor white LED systems. IEEE Trans. Power Electron. 30, 6934-6947 (2016) https://doi.org/10.1109/tpel.2014.2384199

7. S. Xu, H.X. Zhang, Q.B. Zhou, H. Wang, Effects of spectral parameters on the light properties of redgreen-blue white light-emitting diodes. Appl. Opt. 55, 4456-4460 (2016) https://doi.org/10.1364/ao.55.004456

8. H. Kuo, J.K. Sheu, S.J. Chang, Y.K. Su, L.W. Wu, J.M. Tsai, C.H. Liu, R.K. Wu, n-UV+blue/green/red white light emitting diode lamps. Jpn. J. Appl. Phys. 42, 2284 (2016) https://doi.org/10.1143/JJAP.42.2284 
9. Z. Deng, Z.X. Qiu, M.M. Zhang, W.L. Zhou, J.L. Zhang, C.Z. Li, C.Y. Rong, L.P. Yu, S.X. Lian, Tricolor emitting and energy transfer in the phosphor $\mathrm{Ba}_{2} \mathrm{ZnSi}_{2} \mathrm{O}_{7}: \mathrm{Ce}^{3+}, \mathrm{Eu}^{3+}, \mathrm{Eu}^{2+}$ for white-LED based nearUV chips. J. Rare Earths. 33, 463-468 (2015) https://doi.org/10.1016/S1002-0721(14)60441-5

10. Y. Zhong, Z. Ya, H. Shruti, W.R. Zhao, W.D. Zhuang, J. Brgoch, Thermally robust and color-tunable blue-green-emitting $\mathrm{BaMgSi}_{4} \mathrm{O}_{10}: \mathrm{Eu}^{2+}, \mathrm{Mn}^{2+}$ phosphor for warm-white LEDs. Inorg. Chem. 59, 1342713434 (2020) https://doi.org/10.1021/acs.inorgchem.0c01803

11. C. Cui, G.H. Chen, Y. Chen, X.Y. Liu, Preparation and luminescent properties of new YAG: $\mathrm{Ce}^{3+}$ phosphor in glass (PIG) for white LED applications. J. Mater. Sci. Mater. Electron. 29, 13019-13024 (2018) https://doi.org/10.1007/s10854-018-9423-3

12. S. Roh, S. Hur, H.J. Song, I.J. Park, D.K. Yim, D.W. Kim, K.S. Hong, Luminescence properties of $\mathrm{Ca}_{5}\left(\mathrm{PO}_{4}\right)_{2} \mathrm{SiO}_{4}: \mathrm{Eu}^{2+}$ green phosphor for near UV-based white LED. Mater. Lett. 70, 37-39 (2012) https://doi.org/10.1016/j.matlet.2011.11.088

13. Shen, D.F. Zhang, X.W. Fan, G.S. Hu, X.B. Bian, L. Yang, Fabrication and characterization of YAG: Ce phosphor films for white LED applications. J. Mater. Sci. Mater. Electron. 27, 976-981 (2016) https://doi.org/10.1007/s10854-015-3841-2

14. Fan, J. Liu, W.X. Zhou, L.M. Han, Luminescence properties of new red-emitting phosphor $\mathrm{Li}_{2} \mathrm{Al}_{2} \mathrm{Si}_{3} \mathrm{O}_{10}: \mathrm{Eu}^{3+}$ for near UV-based white LED. Opt. Mater. 98, 109499 (2019) https://doi.org/10.1016/j.optmat.2019.109499

15. G. Li, J.H. Lee, T. Mori, Y. Yajima, S. Takenouchi, T. Ikegami, Crystal phase and sinterability of wetchemically derived YAG powders. J. Ceram. Soc. Jpn. 108, 439-444 (2010) https://doi.org/10.2109/jcersj.108.1257_439

16. H. Song, J.W. Miao, M. Wang, X.M. Ji, Fabrication of the aluminoborosilicate YAG glass-ceramic phosphor for white LED. Chinese J. Inorg. Chem. 26, 1975-1980 (2010) https://doi.org/CNKI:SUN:WJHX.0.2010-11-012

17. H. Hsu, C.H. Huang, B.M. Cheng, C.H. Lu, Influence of microemulsion conditions on the VUV-excited luminescence and microstructures of $\mathrm{Y}_{3} \mathrm{Al}_{5} \mathrm{O}_{12}$ : $\mathrm{Eu}^{3+}$ phosphors. Mater. Chem. Phys. 124, 632-638 (2010) https://doi.org/10.1016/j.matchemphys.2010.07.026

18. H. Song, J.W. Miao, S.W. Xu, X.M. Ji, Photoluminescence properties of the $\mathrm{Ce}^{3+}$-doped yttrium aluminum garnet glass-ceramic white LED. J. Optoelectronics. Laser. 21, 1785-1789 (2010) https://doi.org/10.16136/j.joel.2010.12.009.

19. Ding, G. Zhu, W.Y. Geng, Q. Wang, Y.H. Wang, Rare-earth-free high-efficiency narrow-band red-emitting $\mathrm{Mg}_{3} \mathrm{Ga}_{2} \mathrm{GeO}_{8}: \mathrm{Mn}^{4+}$ phosphor excited by near-UV light for white-light-emitting diodes. Inorg. Chem. 55, 154-162 (2016) https://doi.org/10.1021/acs.inorgchem.5b02048

20. Su, Q.L. Zhang, S.F. Shao, W.P. Liu, S.M. Wan, S.T. Yin, Phase transition, structure and luminescence of Eu: YAG nanophosphors by co-precipitation method. J. Alloys Compd. 470, 306-310 (2009)\ https://doi.org/10.1016/j.jallcom.2008.02.045 
21. L.P. Li, F. Qin, Y. Zhou, J.P. Miao, Z.G. Zhang, Experimental insight into the thermal quenching of the $\mathrm{Tb}^{3+}$ ion's green photoluminescence in $\mathrm{CaWO}_{4}$ host. Jpn. J. Appl. Phys. 58, 110909 (2019)https://doi.org/10.7567/1347-4065/ab4f3d

Figures

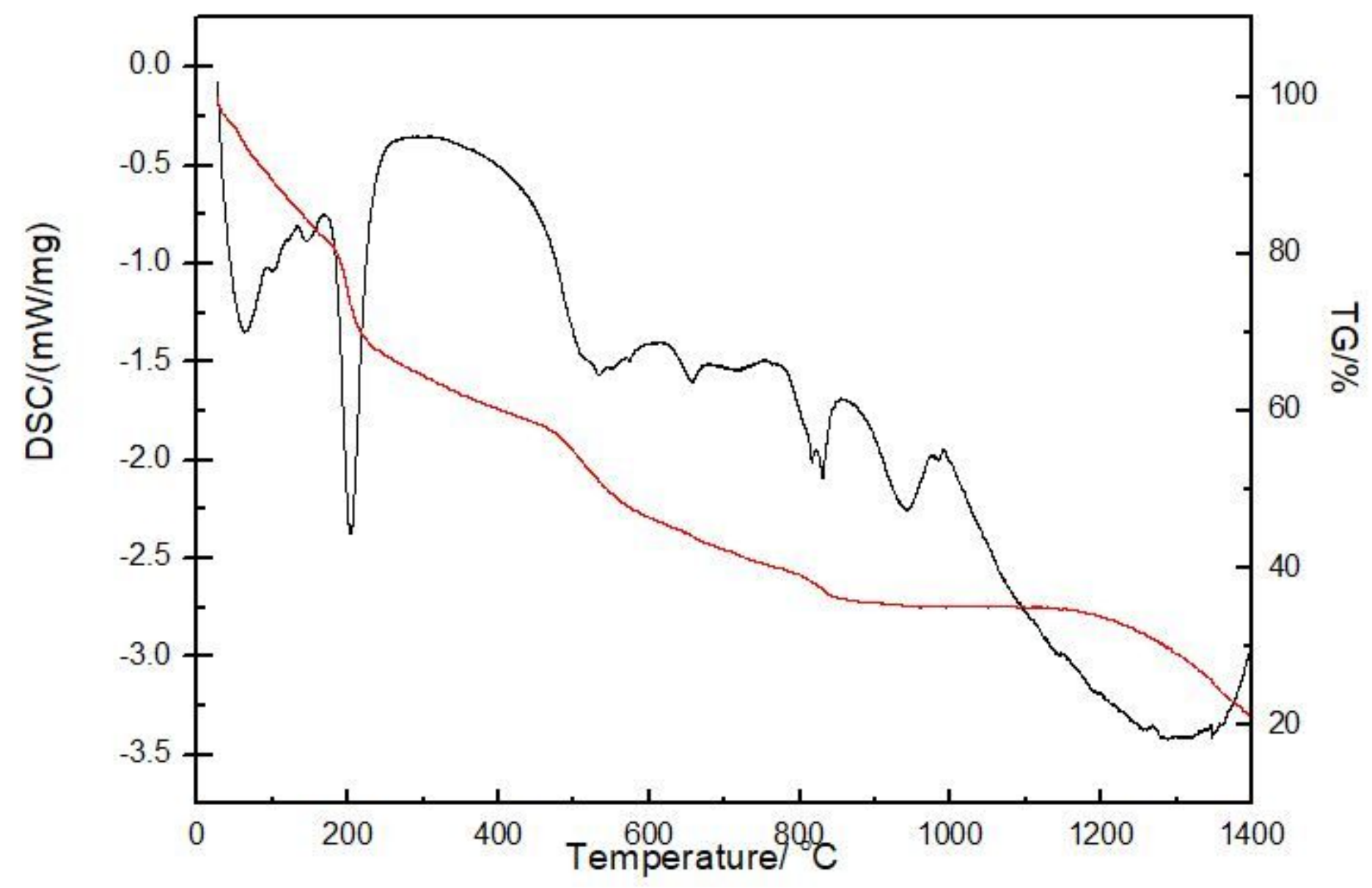

Figure 1

DTA - TGA curve of raw YAG: Eu3+ precursor and glass 


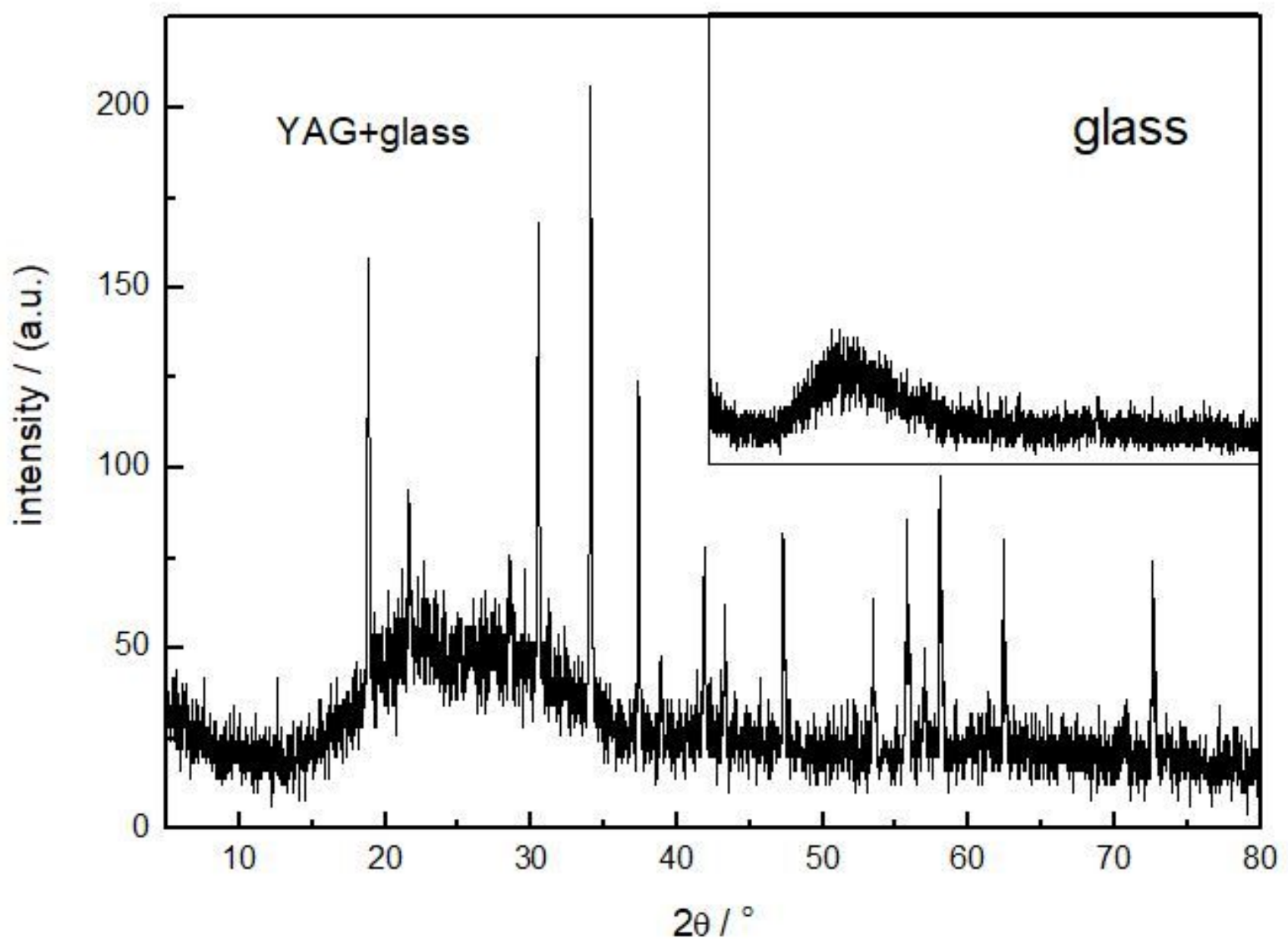

Figure 2

XRD patterns of YAG: Eu3+ fluorescent glass and glass 


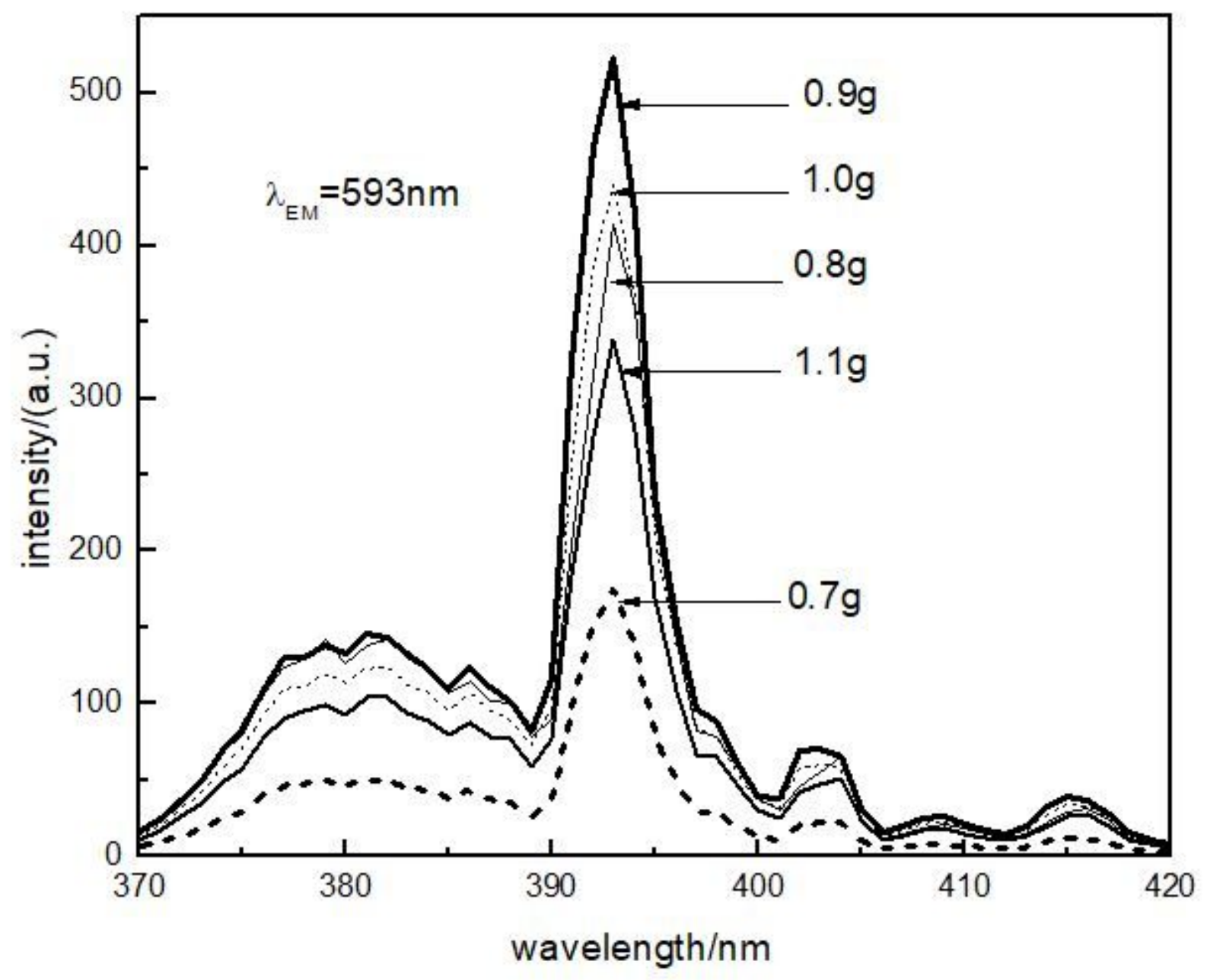

Figure 3

Excitation spectra of fluorescent glass with different content of precursor 


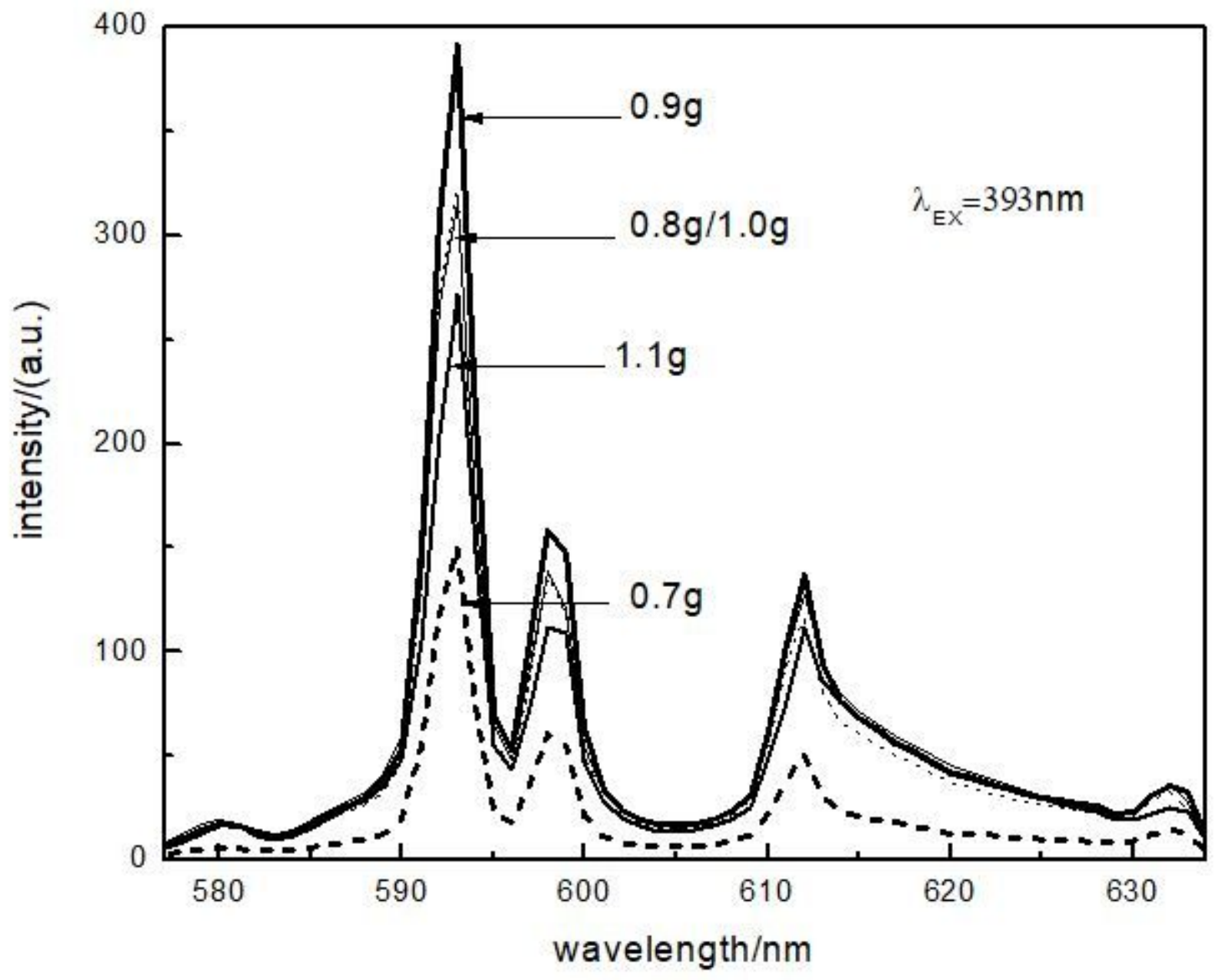

Figure 4

Emission spectra of fluorescent glass with different content of precursor 


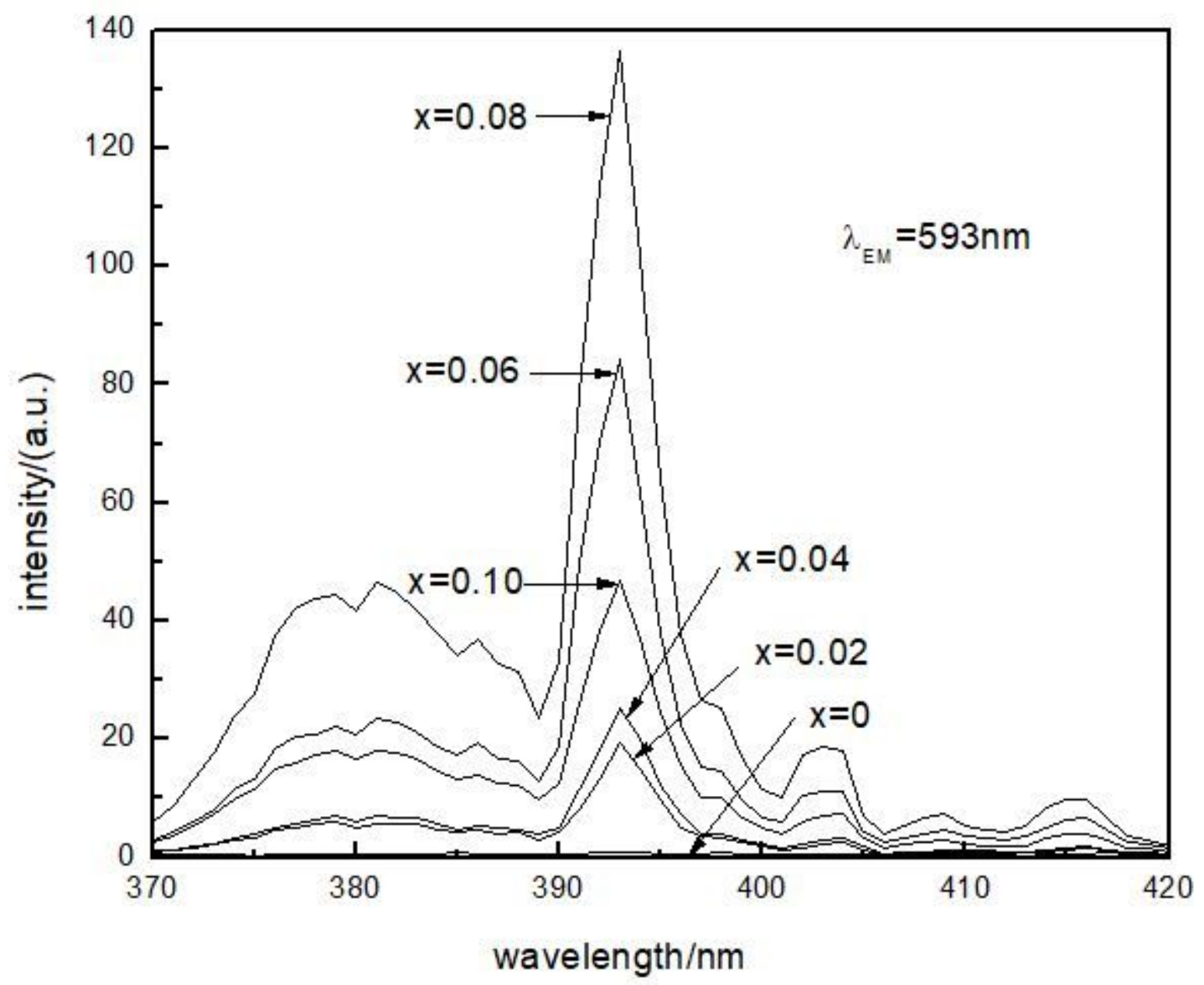

Figure 5

Excitation spectra of YAG fluorescence glass with different content of Eu3+ 


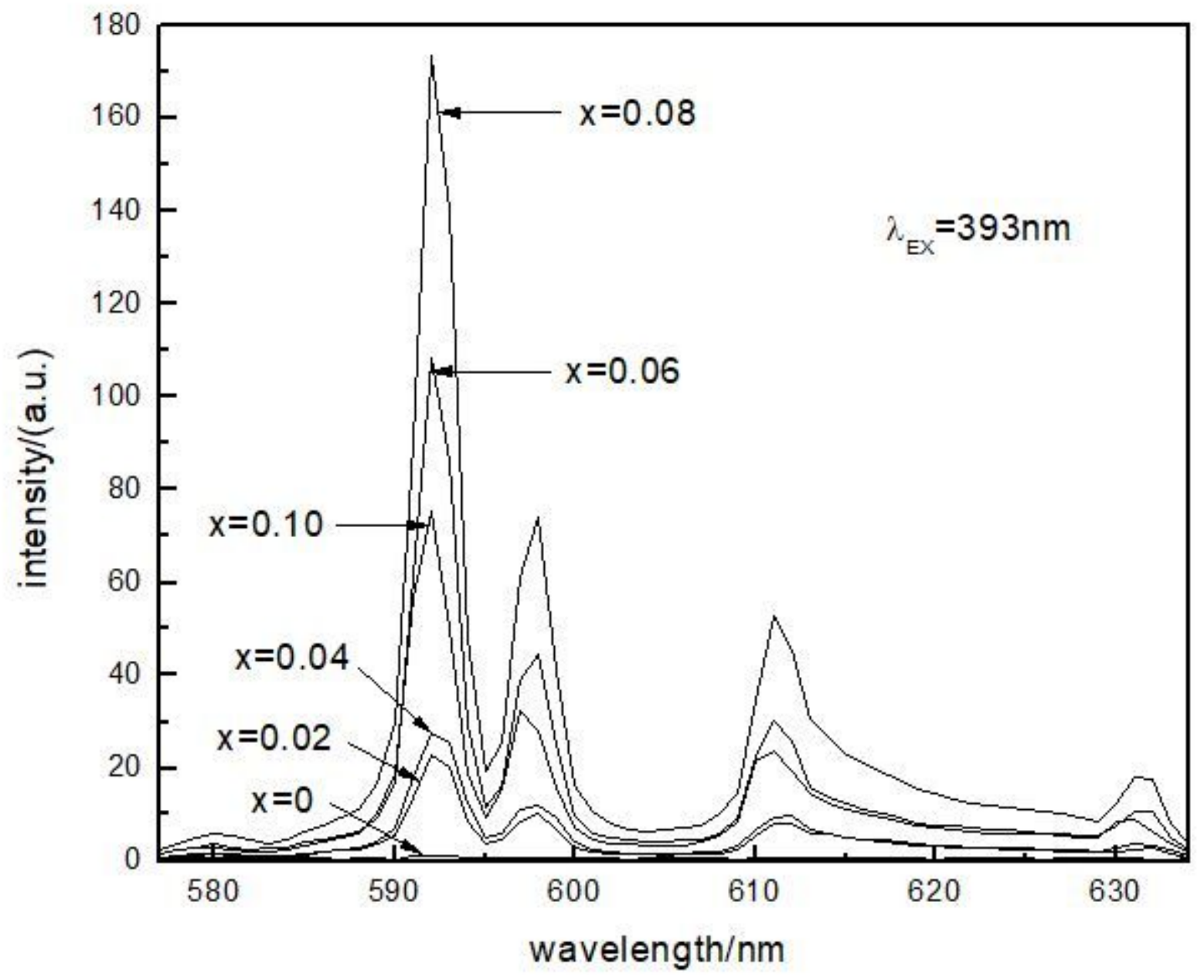

Figure 6

Emission spectra of YAG fluorescence glass with different content of Eu3+ 